\section{Cutaneous leukocytoclastic vasculitis associated with levofloxacin therapy}

\author{
Dana M. Blyth, ${ }^{1}$ Elizabeth Markelz, ${ }^{2}$ \\ Jason F. Okulicz
}

'Department of Internal Medicine and ${ }^{2}$ Infectious Disease Service, San Antonio Military Medical Center, San Antonio, TX, USA

\section{Abstract}

Many cases of cutaneous vasculitis are druginduced with histology revealing leukocytoclastic vasculitis (LCV). We present a case of levofloxacin-associated LCV successfully treated with prednisone and cessation of the offending drug. Although case reports describe a link between LCV and older fluoroquinolones, such as ciprofloxacin and ofloxacin, recent reports have implicated the newer fluoroquinolone levofloxacin. Recognition of fluoroquinoloneinduced cutaneous vasculitis is important as continuation or re-exposure of the offending agent may have life-threatening consequences.

\section{Introduction}

The presentation of vasculitis is highly variable, with more severe cases resulting in hemorrhage, ischemia, or other complications depending on the degree of inflammation and to what extent the vascular architecture is compromised. ${ }^{1}$ For cutaneous vasculitis, up to $20 \%$ of cases are drug-induced with histology demonstrating leukocytoclastic vasculitis (LCV). ${ }^{2}$ The classic presentation of cutaneous vasculitis is palpable purpura, but ranges from erythematous lesions to deep ulcers or digital gangrene. ${ }^{3} \mathrm{~A}$ high index of suspicion is necessary for diagnosis and successful treatment. The identification of drug-induced LCV is critical since withdrawal of the offending agent can be life-saving. ${ }^{4}$ We describe a case of levofloxacin-associated LCV and review the pertinent literature involving the association of fluoroquinolones with cutaneous vasculitis.

\section{Case Report}

A 64-year old man presented for evaluation of a painful, erythematous, and violaceous rash on his left leg that had developed over the previous $24 \mathrm{~h}$. The day before presentation, the patient had completed a 5-day-course of lev- ofloxacin $500 \mathrm{mg}$ twice daily for a presumed respiratory infection. The patient had a history of severe varicose veins in his lower extremities which had led to chronic lower extremity edema after undergoing elective vein removal procedures. Other past medical history included benign prostatic hypertrophy, erectile dysfunction, and a distant history of left great toe osteomyelitis. Medications included felodipine $5 \mathrm{mg}$ daily, hydrochlorothiazide $25 \mathrm{mg}$ daily, terazosin $1 \mathrm{mg}$ daily, vardenafil $5 \mathrm{mg}$ as needed, and the recently prescribed levofloxacin. He denied any use of over the counter or herbal medications.

Patient's vital signs on presentation were body temperature $96.8^{\circ} \mathrm{F}$, pulse $63 / \mathrm{min}$, respiratory rate $18 / \mathrm{min}$, blood pressure $155 / 95$ $\mathrm{mmHg}$, and pulse oximetry $98 \%$ on room air. Examination of his left lower extremity revealed 3-4+ pitting edema. Numerous purpuric papules coalescing into large plaques were present on the medial and anterior distal left leg with dark purple coloration centrally and non-blanching erythema around the periphery of the lesions. There was an approximately $2 \mathrm{~cm}$ in diameter coalesced plaque of palpable purpura on the proximal left lateral leg with a few small bullae centrally as well as scattered purpuric papules on the left thigh. On the dorsum of the left foot there were numerous petechiae that were becoming confluent. He had significant tenderness to palpation on the medial and anterior distal left leg. Several scattered purpuric papules were also present on the right lower extremity. The rest of his physical examination was normal.

Laboratory analysis revealed white blood cell count (WBC) $8.16 \times 10^{9} / \mathrm{L}$ (normal range 3.4$9.8 \times 10^{\%} / \mathrm{L}$ ) with $71 \%$ neutrophils (normal range $41-73 \%)$, 20\% lymphocytes (18-46\%), and $1 \%$ eosinophils (0-3.2\%). Hemoglobin and hematocrit were $14.1 \mathrm{~g} / \mathrm{dL}(14-18 \mathrm{~g} / \mathrm{dL})$ and $42.2 \%$ (41-52\%), respectively, while platelet count was $296 \times 10^{9} / \mathrm{L}\left(142-362 \times 10^{\%} / \mathrm{L}\right)$. His renal function and serum electrolytes were within normal limits. Since cutaneous vasculitis was suspected, based on clinical appearance of palpable purpura, diagnostic testing was carried out to determine the etiology. Complement levels were normal and other tests for potential causes of vasculitis were also negative, including ANA, rheumatoid factor, anti-streptolysin-0, C-ANCA, P-ANCA, and testing for hepatitis B and C. Serum protein electrophoresis demonstrated a normal electrophoresis pattern.

A punch biopsy was performed (Figure 1) and was consistent with leukocytoclastic vasculitis. Upon review of the patient's recent medications, levofloxacin-induced vasculitis was suspected. After the patient confirmed that he was no longer taking levofloxacin, he was prescribed a 7-day course of prednisone $60 \mathrm{mg}$ daily followed by a 14-day taper. A 2-week
Correspondence: Dana M. Blyth, MD, Brooke Army Medical Center, 3851 Roger Brooke Drive, Fort Sam Houston, TX 78234-6200, USA.

Tel: +1.210.916.4355 - Fax. +1.210.916-5900.

E-mail: dana.m.blyth@us.af.mil

Key words: levofloxacin, drug induced cutaneous vasculitis, leukocytoclastic vasculitis, fluoroquinolone.

Contributions: DMB, manuscript preparation, literature research; EM, images providing, case discussion, manuscript review; JFO, manuscript conception, preparation, supervision.

Conflict of interest: the authors do not declare any potential conflicts of interest with this publication.

The views expressed in this article are those of the authors and do not reflect the official policy of the Department of the Army, the Department of Defense, or the U. S. Government.

Received for publication: 23 August 2011.

Revision received: 6 November 2011.

Accepted for publication: 14 November 2011.

This work is licensed under a Creative Commons Attribution NonCommercial 3.0 License (CC BYNC 3.0).

(C) Copyright D.M. Blyth et al., 2012

Licensee PAGEPress, Italy

Infectious Disease Reports 2012; 4:e11

doi:10.4081/idr.2012.e11

course of clindamycin was also given for possible cellulitis due to bacterial super-infection of the area involving LCV. Fluoroquinolones were avoided due to suspicion of levofloxacininduced vasculitis and a concern for a potential cross-reaction among other agents in the same drug class. At follow up one month after his initial presentation, the patient had significant improvement in his lower extremity lesions. In the area of his left lower extremity with the greatest skin involvement, a large but shallow ulceration remained and was treated with local wound care. The rest of the patient's dermatological manifestations had completely resolved.

\section{Discussion}

After evaluation of the patient's clinical history and physical examination findings, a drug-induced cutaneous vasculitis was suspected and later confirmed by biopsy. The interval between the first exposure to the drug and the initial onset of symptoms can range between hours and years, with onset occurring following an increased dose or re-challenge. In cases of drug-induced hypersensitivity vasculitis, discontinuation of the offending agent is 
usually followed by a rapid improvement in symptoms. Re-challenge is not recommended due to the potential of recurrence with increased severity. ${ }^{2}$

Evaluation of a patient with suspected cutaneous vasculitis should include history, physical examination, and laboratory and histological evaluations. ${ }^{5}$ The first step in classifying the lesion is based on caliber of the vessels involved (small, medium, or large) by performing a skin biopsy. LCV involves small vessels and punch biopsy is the diagnostic method of choice. ${ }^{2}$ Since neutrophils are replaced by lymphocytes and macrophages within $48 \mathrm{~h}$ after the appearance of a lesion, early biopsy is of highest diagnostic yield. ${ }^{3}$ Tissue eosinophilia is also suggestive of a drug etiology but is not always present. Direct immunoflourescence confirms and further classifies the presence of vasculitis by identifying specific immunoglobulins. ${ }^{6}$

In drug-induced vasculitis, the offending drug can be hard to identify, and further laboratory tests can be helpful. An ANCA testing is positive in some cases of drug induced vasculitis, including propylthiouracil, hydralazine, allopurinol, minocycline, penicillamine, and phenytoin which may induce systemic vasculitis syndromes with a life-threatening visceral involvement. ${ }^{1}$ Our patient was not prescribed any of the above agents and ANCA testing was

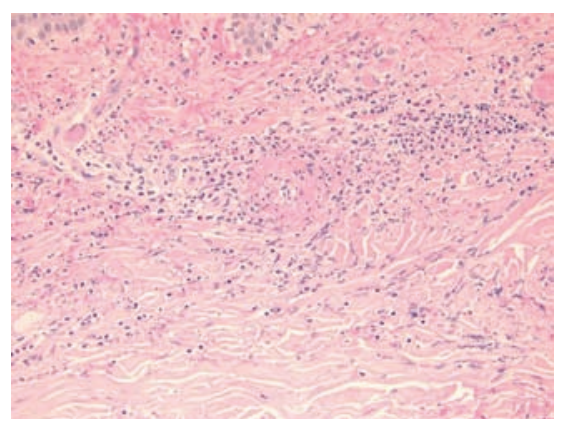

negative. According to the Naranjo adverse drug reaction probability scale with a score of 6 , levofloxacin was a probable cause of LCV in our case as the adverse event occurred after the suspected drug was administered, improved after discontinuation with addition of steroids, was proven by biopsy to be LCV, and

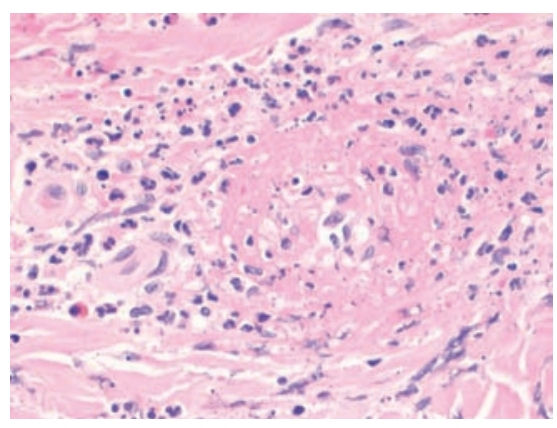

Figure 1. Skin biopsy of left lower extremity with hematoxylin and eosin staining under A) low and B) high power demonstrating a predominant neutrophilic infiltration, presence of eosinophils, and the formation of subepidermal bullae consistent with leukocytoclastic vasculitis.

Table 1. Prior case reports of fluoroquinolone-associated vasculitis.

\begin{tabular}{|c|c|c|c|c|c|c|c|}
\hline $\begin{array}{l}\text { Fluoroquinolone } \\
\text { (FQ) }\end{array}$ & Dose & $\begin{array}{l}\text { Time to } \\
\text { symptom } \\
\text { onset }\end{array}$ & $\begin{array}{l}\text { Other } \\
\text { medications }\end{array}$ & $\begin{array}{l}\text { Clinical diagnosis } \\
\text { or biopsy proven }\end{array}$ & Final diagnosis & Treatment & $\begin{array}{l}\text { Year } \\
\text { Published }\end{array}$ \\
\hline Ciprofloxacin ${ }^{17}$ & $500 \mathrm{mg}$ po BID & 3 days & None & Skin biopsy & $\begin{array}{l}\text { Perivascular } \\
\text { mononuclear-cell infiltrate }\end{array}$ & Withdrawal of FQ & 1989 \\
\hline Ciprofloxacin ${ }^{18}$ & 500 po mg/day & 4 days & Cephradine & Skin biopsy & LCV & Withdrawal of FQ & 1992 \\
\hline Ciprofloxacin ${ }^{18}$ & Unknown & 10 days & Diuretic & Clinical diagnosis & Haemorrhagic vasculitis & None & 1992 \\
\hline Ciprofloxacin $^{19}$ & 500 mg po BID & 4 days & Fluoxetine & Clinical diagnosis & Cutaneous vasculitis & $\begin{array}{l}\text { Withdrawal of FQ; } \\
\text { fluoxetine continued }\end{array}$ & 1997 \\
\hline Ciprofloxacin ${ }^{20}$ & Unknown & 10 days & None & $\begin{array}{l}\text { Clinical diagnosis; } \\
\text { subsequent renal } \\
\text { biopsy }\end{array}$ & Cutaneous vasculitis & $\begin{array}{l}\text { Withdrawal of FQ; } \\
\text { prednisone }\end{array}$ & 2007 \\
\hline Ciprofloxacin ${ }^{4}$ & Unknown & 7 days & Rifampin & Clinical diagnosis & Drug-induced vasculitis & $\begin{array}{l}\text { Withdrawal of FQ; } \\
\text { rifampin given without } \\
\text { recurrence }\end{array}$ & 2009 \\
\hline Ciprofloxacin ${ }^{4}$ & Unknown & 8 days & Flucloxacillin & Clinical diagnosis & Drug hypersensitivity & $\begin{array}{l}\text { Withdrawal of FQ; } \\
\text { flucloxacillin continued }\end{array}$ & 2009 \\
\hline Ofloxacin ${ }^{21}$ & 200 mg po BID & 1 day & None & $\begin{array}{l}\text { Skin biopsy and mast } \\
\text { cell degranulation test } \\
\text { for ofloxacin }\end{array}$ & Leukocytoclastic angiitis & $\begin{array}{l}\text { Withdrawal of FQ; } \\
\text { prednisone }\end{array}$ & 1989 \\
\hline Ofloxacin 22 & 200 mg po BID & 5 days & $\begin{array}{l}\text { Bumetanide, } \\
\text { spirinolactone } \\
2 \text { weeks prior }\end{array}$ & Skin biopsy & Vasculitis & Unknown & 1989 \\
\hline Ofloxacin ${ }^{23}$ & 200 mg po BID & 3 days & $\begin{array}{l}\text { Aspirin, } \\
\text { digoxin }\end{array}$ & Skin biopsy & $\begin{array}{l}\text { Leukocytoclastic } \\
\text { vasculitis }\end{array}$ & $\begin{array}{l}\text { Withdrawal of FQ; } \\
\text { prednisolone }\end{array}$ & 1995 \\
\hline Ofloxacin ${ }^{24}$ & 200 mg po BID & 3 days & None & Skin biopsy & Leukocytoclastic angiitis & Withdrawal of FQ & 1996 \\
\hline Levofloxacin ${ }^{25}$ & 500 mg po daily & 3 days & None & Clinical diagnosis & $\begin{array}{l}\text { Nephrotoxicity and } \\
\text { purpura }\end{array}$ & $\begin{array}{l}\text { Withdrawal of FQ; } \\
\text { prednisone }\end{array}$ & 2002 \\
\hline Levofloxacin ${ }^{26}$ & 500 mg po daily & 5 days & $\begin{array}{l}\text { Azithromycine, } \\
\text { piperacilline- } \\
\text { tazobactam }\end{array}$ & Clinical diagnosis & LCV & $\begin{array}{l}\text { Withdrawal of FQ; } \\
\text { prednisone }\end{array}$ & 2006 \\
\hline Levofloxacin ${ }^{4}$ & Unknown & 3 days & Rifampin & Skin biopsy & LCV & $\begin{array}{l}\text { Withdrawal of FQ and } \\
\text { rifampin changed to } \\
\text { rifampicin }\end{array}$ & 2009 \\
\hline Levofloxacin & $500 \mathrm{mg}$ po BID & 5 days & None & Skin biopsy & LCV & $\begin{array}{l}\text { Withdrawal of FQ; } \\
\text { prednisone }\end{array}$ & $\begin{array}{l}\text { Current } \\
\text { case }\end{array}$ \\
\hline
\end{tabular}


no other alternative causes for the reaction were identified. ${ }^{7}$ Levofloxacin is a commonly prescribed antibiotic and is indicated for a number of infections, including community acquired and nosocomial pneumonia, uncomplicated or complicated urinary tract infections and pyelonephritis, acute bacterial sinusitis, acute or chronic bronchitis, as well as skin and skin structure infections. . $^{8-10}$

Adverse events commonly associated with fluoroquinolones as a class include: gastrointestinal and CNS toxicity, EKG abnormalities including QT prolongation, dysglycemia, phototoxicity, tendon and joint disorders, hypersensitivity reactions, and hepatotoxicity. ${ }^{11-13}$ While some structural components are clearly associated with adverse reactions, such as phototoxicity with the addition of chlorine or fluorine at the 8-position, and CNS effects which are seen more commonly with the unsubstituted 7-piperazine derivatives, others do not appear to have any obvious structural associations including QT prolongation ${ }^{14}$ and tendon rupture. ${ }^{12}$ In previous studies, ciprofloxacin, ofloxacin, levofloxacin, moxifloxacin and gatifloxacin have been associated with torsades de pointes. ${ }^{15}$ However, the development of torsades de pointes is likely influenced by multiple risk factors in a patient already at risk. ${ }^{16}$ In other reports, ciprofloxacin has been the predominant fluoroquinolone associated with cutaneous vasculitis.

All reported cases of fluoroquinolone-associated LCV in the literature involve ciprofloxacin, ofloxacin, and levofloxacin (Table 1). This association may be due to structural similarities between these agents. For example, levofloxacin is the L-enantiomer of ofloxacin. ${ }^{27}$ Ciprofloxacin is distinguished by a cyclopropyl group at position 1 of the molecule and has other structural differences compared to ofloxacin and levofloxacin. While ciprofloxacin has an unsubstituted piperazine ring and levofloxacin and ofloxacin have a 4-methyl piperazine at position 7 , there is great variability at position 7 in other fluoroquinolones. ${ }^{28,29}$ Despite some similarities in structure, the association of LCV with ciprofloxacin, ofloxacin and levofloxacin may also be attributed to their predominant use in clinical practice.

For all reported cases in the literature, the duration of fluoroquinolone therapy was 4-10 days. Many were clinically diagnosed without histological confirmation, but they reveal a theme of recovery following withdrawal of the agent as seen in our case. Cutaneous vasculitis may be limited to skin which offers a better prognosis, but can involve other organs with small-vessels including the kidney, ${ }^{30}$ as has been reported in one case report involving ciprofloxacin $^{20}$ and another involving levofloxacin. ${ }^{26}$ In comparison to previous reports of levofloxacin-induced vasculitis, our case had several additional elements that may have con- tributed to the patient's risk of developing LCV. Following review of medical records, the patient had previously been prescribed 2 courses of ciprofloxacin, eight months and five years prior to his course of levofloxacin, with no reported adverse effects. It is not known whether previous courses of ciprofloxacin could have been sensitizing events for later development of LCV upon challenge with levofloxacin. Levofloxacin was noted as an allergy in the patient's medical record and the patient was counseled to avoid fluoroquinolones in the future.

\section{Conclusion}

Consistent with previous case reports involving ciprofloxacin and ofloxacin, levofloxacin was a probable cause of LCV in our patient according to the Naranjo adverse drug reaction probability scale. ${ }^{7}$ As in previous case reports, our patient had a full recovery with prednisone treatment and withdrawal of levofloxacin. Recognition of drug-induced vasculitis is critical as LCV can be life-threatening without discontinuation of the offending agent. Review of current literature shows that LCV has been associated with fluoroquinolones including ciprofloxacin, ofloxacin, and levofloxacin, but has yet to be reported in association with other agents in the fluoroquinolone class.

\section{References}

1. Carlson JA, Cavaliere LF, Grant-Kels JM. Cutaneous vasculitis: diagnosis and management. Clin Dermatol 2006;24:414-29.

2. Chen KR, Carlson JA. Clinical approach to cutaneous vasculitis. Am J Clin Dermatol 2008;9:71-92.

3. Carlson JA. The histological assessment of cutaneous vasculitis. Histopathology 2010; $56: 3-23$.

4. Maunz G, Conzett T, Zimmerli W. Cutaneous vasculitis associated with fluoroquinolones. Infection 2009;37:466-8.

5. Gibson LE, Su WP. Cutaneous vasculitis. Rheum Dis Clin North Am 1995;21:1097113.

6. Gibson LE. Cutaneous vasculitis update. Clin Dermatol 2001;19:603-15.

7. Naranjo CA, Busto U, Sellers EM. A method for estimating the probability of adverse drug reactions. Clin Pharmacol Ther 1981; 30:239-45.

8. Schaeffer AJ. The expanding role of fluoroquinolones. Am J Med 2002;113:45S-54S.

9. Garrison J, Hooton TM. Fluoroquinolones in the treatment of acute uncomplicated urinary tract infections in adult women. Expert Opin Pharmacother 2001;2:1227-37.
10. Noreddin AM, Elkhatib WF. Levofloxacin in the treatment of community acquired pneumonia. Expert Rev Anti Infect Ther 2010;8:505-14.

11. Bolon MK. The newer fluoroquinolones. Infect Dis Clin N Am 2009;23:1027-1051.

12. Liu, Hans H. Safety profile of the fluoroquinolones focus on levofloxacin. Drug Safety 2010;33:353-69.

13. Owens RC, Ambrose PG. Antimicrobial safety: focus on fluoroquinolones. Clin Infect Dis 2005;41:S144-57.

14. Ball P. Quinolone generations: natural history or natural selection? J Antimicrob Chemother 2000;46:17-24.

15. Frothingham R. Rates of torsades de pointes associated with ciprofloxacin, ofloxacin, levofloxacin, gatifloxacin, and moxifloxacin. Pharmacotherapy 2001;21: 1468-72.

16. Owens RC, Ambrose PG. Torsades de pointes associated with fluoroquinolones. Pharmacotherapy 2002; 22:663-72.

17. Choe U, Rothschild BM, Laitman L. Ciprofloxacin-induced vasculitis (Letter). N Engl J Med 1989;320:257.

18. Stubbings J, Sheehan-Dare R, Walton S. Cutaneous vasculitis due to ciprofloxacin. Br Med J volume 1992;305:29.

19. Lieu PK, Tok SC, Ismail NH, Chng HH. Ciprofloxacin-induced cutaneous vasculitis. Allergy 1997;52:593-600.

20. Storsley L, Gerldenhuys L. Ciprofloxacininduced ANCA-negative cutaneous and renal vasculitis-resolution with drug withdrawal. Nephrol Dial Transpl 2007;22:66072.

21. Huminer D, Cohen J, Majadla R, Dux S. Hypersensitivity vasculitis due to ofloxacin. Br Med J 1989;299:303.

22. Pace JL, Gatt P. Fatal vasculitis associated with ofloxacin. Br Med J 1989;299:658.

23. Berrin BC, Lawrence R, Sungur M, et al. Ofloxacin-induced vasculitis. Internal Medicine 1995;34:872-4.

24. Pipek, Ruben, et al. Ofloxacin-induced hypersensitivity vasculitis. Am J Med Sci 1996; 311:82-3.

25. Famularo G, De Simone C. Nephrotoxicity and purpura associated with levofloxacin. Ann Pharmacother 2002;36:1380-2.

26. Zaigraykin N, Kovalev J, Elias N, Naschitz J. Levofloxacin-induced interstitial nephritis in an elderly woman. Isr Med Assoc J 2006;8:726-7.

27. Walker RC. The fluoroquinolones. Mayo Clin Proc 1999;74:1030-7.

28. Van Bambeke F, Michot JM, Tulkens PM. Quinolones in 2005: an update. Clin Microbiol Infect. 2005;11:256-80.

29. Appelbaum PC, Hunter PA. The fluoroquinolone antibacterials: past, present, and future perspectives. Int J Antimicrob Agents 2000;16:5-15.

30. Gonzales-Gay MA, Garcia-Porrua C, Pujol RM. Clinical approach to cutaneous vasculitis. Current Opin Rheumatol 2004;17: 56-61. 